\title{
A BPM-based framework for the impact assessment of blockchain to the midstream LNG supply chain
}

\author{
Dimitrios V. Lyridis, Georgios O. Andreadis, Christos Papaleonidas \\ and Violetta Tsiampa \\ Laboratory for Maritime Transport, \\ School of Naval Architecture and Marine Engineering, \\ National Technical University of Athens, Zografos, Greece
}

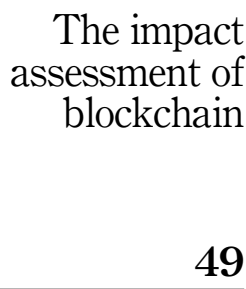

Received 23 March 2021

Revised 29 July 2021

15 September 2021

Accepted 21 September 2021

\begin{abstract}
Purpose - The current study addresses how blockchain can deal with the challenges that the midstream liquefied natural gas (LNG) supply chain poses combined from a management standpoint. Such challenges are: the volume of transactions, communication hurdles and the lack of contemporary management tools. The paper proposes a comprehensive framework to assess the impact of blockchain implementation in the midstream LNG supply chain in order to tackle those barriers.

Design/methodology/approach - The basis of the research is the business process modelling (BPM), through which entities, roles, tasks, resources and transactions can be modelled and simulated. The modelling of the midstream LNG supply chain, via BPM, is based on guidelines of the Society of International Gas Tanker and Terminal Operators (SIGGTO) and common industry business models. A quantitative analysis is employed to support the motivation and the potential impact of blockchain implementation. The methodology is used to identify (1) inefficiencies related to large volume of transactions between stakeholders and (2) critical areas of an LNG shipping company, where blockchain can be implemented.

Findings - Process repeatability, numerous shared documentation forms, excessive paperwork and communication imbroglios are mapped from the modelling section. Up to 327 processes are repeated during a typical vessel voyage, and up to 122 shared documentation forms are exchanged. Excessive paperwork and communication imbroglios are tracked through, which correspond to 25 severe errors as detected. By implementing the methodology, stakeholders can quantify the possible impact of blockchain on the operational performance of each stakeholder's operations separately and the supply chain as a whole in terms of real-time monitoring, transparency and paperwork reduction, time and cost savings.

Research limitations/implications - The research has certain limitations deriving from its conceptual nature. The business processes' modelling is based on standard procedures described in the guidelines by SIGGTO and may need further adjustment for specific use cases. A structured case study has not been realisable as corporate data for an LNG shipping company regarding processes and other commercial sensitive information are required.

Practical implications - Potential practitioners may exploit the proposed framework as a low cost and seamless tool to evaluate how blockchain could disrupt their operations. Thus, the blockchain implementation's improvements or weaknesses can be pinpointed, and enabling the interested stakeholder of the LNG supply chain with specific feedback, it can guide them towards informed decisions on their operations.

Originality/value - The research has a novel approach as it combines the creation of practical management framework, with a comprehensive visualization of the midstream LNG supply chain. Thus, the reader can identify in which parts of the midstream LNG supply chain can blockchain be implemented, and what impact it could have in terms of supply chain operations.
\end{abstract}

Keywords LNG supply chain, LNG shipping, Blockchain, Business process modelling, Operations optimization

Paper type Research paper

(C) Pacific Star Group Education Foundation. Licensed re-use rights only.

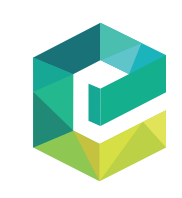

Maritime Business Review Vol. 7 No. 1,2022 2397-3757 DOI 10.1108/MABR-03-2021-0023 
MABR

7,1

50

\section{Introduction}

Effective management should encompass technological trends, which can be implemented by the respective company involving numerous departments, human and material resources, and activities. Blockchain is a contemporary subject over which the shipping industry has been showing increasing interest (Lyridis and Papaleonidas, 2019). Shipping, as part of wider supply chains, is ideal for the development of blockchain applications due to the complexity, the plethora of stakeholders (shipping companies, product exporters and importers, ports, warehouses, terminals, agents, brokers, customs, insurance companies and governmental authorities) (Xu et al., 2018). In this regard, Pu and Lam (2020) analysed the different maritime industry sectors offering the potential for deploying blockchain applications and proposed a relevant conceptual framework for future research.

This paper aims to explore the impact of a potential application of blockchain technology on the liquefied natural gas (LNG) supply chain, focussing on the midstream part. The LNG industry has been put into focus for several reasons. First, data highlight the industry's significant growth. The world seaborne trade of LNG has increased from 246.55 million $\mathrm{m}^{3}$ in 2011 to 361.84 in 2020, following a significant growth of both liquefaction and regasification capacity (Clarksons Shipping Intelligence, 2021). Next, liquefaction capacity has increased from 280.84 million $\mathrm{m}^{3}$ in 2011 to 423.04 in 2020 , and regasification capacity has increased from 663.60 million $\mathrm{m}^{3}$ in 2011 to 915.08 in 2020 (Clarksons Shipping Intelligence, 2021).

A second reason is that the LNG industry's potential development will add to the already highly complex operational environment. The flexibility of the current and future LNG midstream supply chain that derives from the various strategies, business models and multilateral contractual relationships adds to the existing complexity. When focussing on the midstream part of the LNG supply chain, the definition of the most common business models, contractual framework and physical processes lead to potential knuckle points and dysfunctions related to time, transparency and work distribution. Countering those issues may reduce LNG shipping costs and order process time.

The paper is structured in four sections. Section 2 elaborates on the theoretical background of the LNG supply chain's examined topics, its inherent business models and blockchain fundamentals. It builds on the example of other industries, which have paved the way and implemented blockchain to improve their operations in the above-referenced context. While the shipping industry has progressed with pilot blockchain applications, LNG shipping companies have not done so. A potential showstopper may be the operational nature of the LNG shipping market. LNG shipping works under chartering agreements, where a lack of integration between stakeholders prevails instead of the integration demonstrated by the liner market. This is the reason why most pilot blockchains in shipping focus on the liner market.

Following the description of blockchain technology, the following question is raised: How can one demonstrate, in a seamless yet coherent manner, the potential benefits of blockchain technology implementation in industries like shipping that are critical to the LNG supply chains? In order to provide an answer, this question can be decomposed into two subquestions since the subject being analysed requires a structured approach. First, in which parts of the midstream LNG supply chain can blockchain be implemented? In addition, what is its impact in terms of supply chain operations?

To reach a meaningful conclusion, the authors claim that they need to employ a specific methodology, namely the business process modelling (BPM) concept, to address the question posed. BPM can be characterised as a solid framework due to its versatility in examining and re-engineering business processes. The BPM concept allows the authors to model the entire LNG supply chain processes up to a generic level, focussing on displaying a detailed view of the midstream section (shipping, loading and discharging operations) and analyse the structure of the organisations involved. Besides, it is relatively seamless because it will not 
disturb the actual operation of the LNG supply chain stakeholders. A quantitative analysis of an actual LNG fleet adds to the discussion of the questions mentioned above and underlines the motivation behind the current research. Several benefits can be inferred by a series of structured hypotheses that the authors have applied to endorse the value chain generated by blockchain adoption.

Section 3 details further the BPM concept by demonstrating the relationship between processes and process holders. The diagrams highlight all the interactions between supply chain stakeholders where blockchain can be applied, thus streamlining operations, extracting added value and offering quantified benefits. The research hypothesis is that a BPM-based framework can be used to identify specific transactions within a supply chain where blockchain can be applied and assess its impact on supply chain performance. Furthermore, the synergy between the technologies of BPM and blockchain is a significant novelty of the research, in the sense that the model representing the midstream LNG supply chain is used to identify areas of the LNG supply chain where the latter can be implemented.

Finally, Section 4 elaborates on the contribution of this novel concept by posing a set of questions to both the academic and business communities.

\section{Theoretical background}

\subsection{Blockchain technology}

Although blockchain has become widely known due to cryptocurrencies, it is far more than that; in fact, it is the core of cryptocurrency applications for a reason. Blockchain is essentially a digitally distributed ledger where every information and transaction are recorded (Crosby et al., 2016; Iansiti and Lakhani, 2017). It is a distributed database solution that holds a continuously growing list of data records stored in a decentralised manner. Instead of being stored in a central server, they are distributed across the ledger participants. Despite how contradictory it may seem, the decentralised nature of blockchain enables its users to track and trace data, which are validated and verified upon entering into the ledger. Transactions to be recorded in the chain have to be confirmed by the participating nodes.

Based on the nature of data accessibility, there can be three types of blockchain: public, private and hybrid (Lin and Liao, 2017). Users have open access to public blockchains, meaning that they can add data to the ledger, maintain it and have permission to weigh in on issues requiring consensus. A better comprehension of the blockchain types listed above and their impact on the supply chain requires defining some of its 'shared ledger' concepts and permission policies. The 'shared ledger' concept means keeping records of all data and transactions across a business network, in the present research, the LNG supply chain.

The problem with blockchain is that data transparency can become a barrier to its adoption; the ledger is open to all the peers so that sensitive data may be exposed to the public (Shen and Zhu, 2020). This may hinder users from sharing data. Some stakeholders may be willing to expose their sensitive business information in the blockchain frame, provided that their shared data can only be visible to restricted users. Clarifying issues related to the distributed ledger's technical understanding and security concept and advantages could remove this barrier. For example, restricting access to data and transaction details could enhance the data-stored security in the blockchain and allow participants to specify which information they share with others. Some blockchain participants may be given access to a broader range of transactions, whereas others may be authorised to view only certain transactions. For instance, an LNG company sells a cargo to an international commodity trader, and both parties can see the transaction details. However, an LNG shipping company can see that the seller and the buyer have transacted but will not see all the transaction details. This is possible through the use of cryptographic technology in the form of digital certificates issued by a single managing authority in the blockchain network when specific conditions are met.
The impact assessment of blockchain 
MABR

7,1

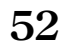

Smart contracts are a typical application of the abovementioned concepts. A so-called smart contract is nothing more than a set of rules stored in the blockchain governing a specific business transaction. For example, a use case scenario in the maritime industry is when a sales purchase agreement (SPA) is translated on the ethereum or NEO blockchain platform using a smart contract. The definition 'smart' is explained by the fact that it is executed automatically. A SPA may have many clauses like all contracts, including financial trades and services, payment deadlines, insurance, credit authorisation and legal processes. These could be made partially or fully self-executing, self-enforcing or both once the conditions of the agreement are met. Blockchain enables increased security as decentralisation makes attacking even half of the nodes nearly impossible. Compared to traditional contracts, the shared database reduces the costs and delays because there is no need for a third party, like a bank, a broker or a government. Since 2017, smart contract use cases have been gradually developed and tested in the maritime industry. Such use cases fall into four fields: electronic bills of lading, ship operations, ship finance and marine insurance (Pu and Lam, 2020).

Notwithstanding the progress made in the subject matter, there are still a few blockchain applications in the shipping industry, which exploit dominant characteristics such as extensive interactions, contracts, regulations and confirmation notes, which may cause delays and money loss. For instance, the motivation behind Maersk's 2017 blockchain project was the 14-30 days door-to-door shipment, to which an additional three-day period can be added due to documentation and other issues related to shipping processes (Bajpai, 2017). With the excessive dependency on paperwork, a complex ecosystem, like the shipping industry as part of the supply chain, could greatly benefit from a robust digital platform to improve all transactions. Following the pilot project, Maersk and IBM continue developing their blockchain platform, TradeLens, to bring business value through emerging technology (Jensen et al., 2019).

Other joint industrial projects followed the example set by Maersk and IBM and planned to explore blockchain technology, many of which are referenced below and are described in detail by Di Gregorio and Nustad (2017). Consortia of liner companies, terminal operators, software companies set most of them, which aim to digitalise data, documentation and transaction details to blockchain and share them among the participants, thus improving speed, transparency and collaboration (Furness-Smith, 2017; Kang, 2017; Zeng, 2017). Another tested blockchain application is its usage to conduct trade transactions between parties for a specific cargo to reduce the processing time and monitor cargo movement (Reuters, 2018; Chambers, 2018; Wei, 2017). Additional research-oriented efforts are at a stage of development (Di Gregorio and Nustad, 2017). Indicative initiatives are: (1) the cooperation between the Malaysia Institute of Supply Chain Innovation with Shanghai Jiaotong University and (2) the Maritime Blockchain Labs set up by Lloyd's Register Foundation and Blockchain Labs for Open Collaboration (BLOC). The latter initiative includes implementing a blockchain in collaboration with GoodFuels Marine to conduct the world's first bunker delivery and transaction. This process provides its participants (shipowners, shippers and charterers) with traceability of the marine bunkering transactions along the supply chain up to the vessel's fuel tank.

Large integrated energy organisations, operating along the LNG supply chain, including shipping, have been working on blockchain projects (McCaw, 2018). BP, Wien Energie and Canadian blockchain start-up BTL worked together and successfully tested a trading system. This is an affirmation of BP's interest to implement the technology in their European gas trading operations. Eni Trading \& Shipping and the Centrica, Engie and Royal Dutch Shell Consortium have shown the same interest. The consortium has initiated an international energy blockchain, the Energy Web Foundation, a public enterprise-grade blockchain platform. Although these three organisations started the effort, many global energy companies and blockchain developers have joined. 
Tramp shipping companies, being a critical part of the LNG supply chain, will be affected by the digitalisation trend, overcoming the reluctance that shipowners show to adopt emerging technologies over their business function. While LNG shipping companies cannot abandon current management tools, they can adopt elements of a process-centric orientation to meet the objectives outlined in their strategic planning, to the benefit of the different stakeholders, namely shipowner(s), the shareholders (if listed in a stock market), the personnel and the clients (Jeston, 2018). The fact that shipping is one of the biggest industries is apodictic. The implementation of intelligence systems can further lead its growth, lifting off its efficiency and productivity through the collaboration of automation and software systems, such as blockchain. The authors believe that the advantages of blockchain would be significant and must be further explored. To this end, a conceptual framework is proposed next to enable LNG shipping companies to seamlessly evaluate the impact of blockchain on their operations.

\subsection{The LNG supply chain}

First, a comprehensive overview of the LNG physical supply chain is required to elaborate further on its business view and on the parts of the chain from where value is extracted for each stakeholder. Subsequently, the focus shifts to commercial issues affecting the LNG projects, players and various drivers affecting the development of these projects and business models found in the market today.

The LNG industry involves several facilities corresponding to the different stages of the supply chain, namely liquefaction (upstream), shipping (midstream) and regasification (downstream). Initially, natural gas is extracted from onshore or offshore fields, processed and purified before its liquefaction. Then, the processed natural gas is cooled down to approximately $-162^{\circ} \mathrm{C}$, transforming it into a liquid, reducing its volume to about $1 / 600$ of its volume in a gaseous state (Han and Lim, 2012). Notwithstanding the economic feasibility of storage and long-distance transportation of LNG, this also removes several obstacles such as (1) access to natural gas (even by those countries with limited natural gas reserves), (2) limited access to long-distance transmission pipelines and (3) security of supply due to geopolitical risks. Being a liquid, LNG is transported via specialised LNG Carriers (LNGC) (Zoolfakar et al., 2014) and discharged at import terminals, either onshore terminals or floating storage regasification units (FSRU).

The LNG import terminal is the final link in the maritime LNG chain and the end-users connection point (Papaleonidas et al., 2020). The LNG is stored in cryogenic storage tanks and vaporised, to be distributed as a gas through the local network in line with regulatory and end-user requirements. An LNG import terminal's specific design and layout depend on multiple factors: the nearby pipeline takeaway capacity, the size of LNG tankers expected to use the terminal, water depth, topography, geotechnical characteristics and surroundings of the site, the applicable regulatory regime. Typically, onshore LNG terminals are close to densely populated areas and industrial areas, where a diverse range of customers are located. However, large tracts of land with adequate marine access for LNG ships are difficult to locate in densely populated areas as local communities raise environmental and safety/security concerns. Furthermore, protracted planning and regulatory approval for a new LNG terminal permit are time-consuming and very costly. Offshore LNG receiving terminals are an alternative to circumvent all the difficulties above.

\subsection{Business models within the LNG supply chain}

During its early stage, the LNG market was a relatively closed conservative market. Few import and export terminals were developed and controlled by the host country's state entities (Tusiani and Shearer, 2016). Most of the produced LNG was sold directly to
The impact assessment of blockchain 
MABR

7,1

54

creditworthy gas or electric utility buyers from specific projects, and project economics depended on long-term contracts with relatively inflexible terms. As the LNG industry has grown and diversified, more sophisticated supply chain structures and contractual interactions have developed with more flexible, mid- to short-term LNG trading agreements. This trend may expand during the upcoming years. Mimicking the structure of gas contracts in terms of flexibility makes LNG contract prices gradually interconnected with gas hub prices. Innovative contracts are now using LNG spot prices, price reviews, with binding arbitration in the event of failure to agree to expand (Trimble, 2018).

In an evolving market environment, reflected by the shift of contracts, there has been a transition from more traditional business models to less integrated ones where stakeholders tend to shift their roles, extract value and supply the chain, albeit with increased risk exposure. This trend emphasises that international and state-owned integrated oil and gas organisations maintain an investment portfolio participating both in upstream, midstream and downstream LNG projects. In addition, the plurality of supply chain stakeholders means that solid contractual relationships between parties and related infrastructure ensure efficient operation.

In joint ventures where the upstream and downstream infrastructures are owned and operated separately, revenues are split, according to an agreed formula, between the affiliated parties. Along with the revenues, the risk is also allocated, and, in several instances, representatives of the buyer may participate and extract value only from their equity positions in LNG shipping and regasification to tie in with their gas trading businesses in emerging deregulated gas markets. Similarly, IOCs NOCs or joint ventures extract value solely from the non-operated equity interests in developing upstream components of the LNG supply chain like liquefaction plants and gas fields. The benefits of the split revenue concept are long-term security of supply, guaranteed long-term, low-risk return on investment (ROI). In addition, the benefits and the straightforward nature of the traditional model provide projects with access to financing, with limited credit risks for lenders (Ledesma and Fulwood, 2019).

The LNG market evolved concurrently with developing a more contemporary business model, the so-called tolling-merchant model. On this occasion, multiple LNG supply chain stakeholders (sellers, buyers, traders and independent parties) invest in export and import infrastructure. They can freely trade LNG based on global or regional LNG price indices. LNG trading under this model can be conducted under flexible short-term contracts, which narrowly exceed $32 \%$ of total volume traded (GIIGNL, 2020), driven mainly by the cargo availability to meet demand and spot LNG prices. The LNG market's transformation makes it an ideal candidate for extensive blockchain technology application.

\subsection{Quantitative analysis}

2.4.1 Structure and assumptions. To display the impact of the proposed conceptual framework, a quantitative analysis is presented in this section. To meet this objective, the authors planned a relatively simple yet well-structured case based on data for a real LNGC fleet presented in Figure 1. The data were retrieved from public accessible sources and are then processed according to the methodology set in section 2 of the current paper. Through its results, the tangible benefit of blockchain adoption in the LNG supply chain is underlined under the assumption of an all-party agreement on implementing a technically feasible permissioned blockchain.

The BPM of the LNG midstream supply chain operations is based on previous work (Andreadis et al., 2020). In this study, ARIS (Architecture of Integrated Information Systems) by Software AG is used to develop specifically the BPM lifecycle. ARIS is selected because it provides a supporting tool for modelling, executing, analysing and optimising business strategies. It enables the user to focus on the information that is to be exchanged, between 


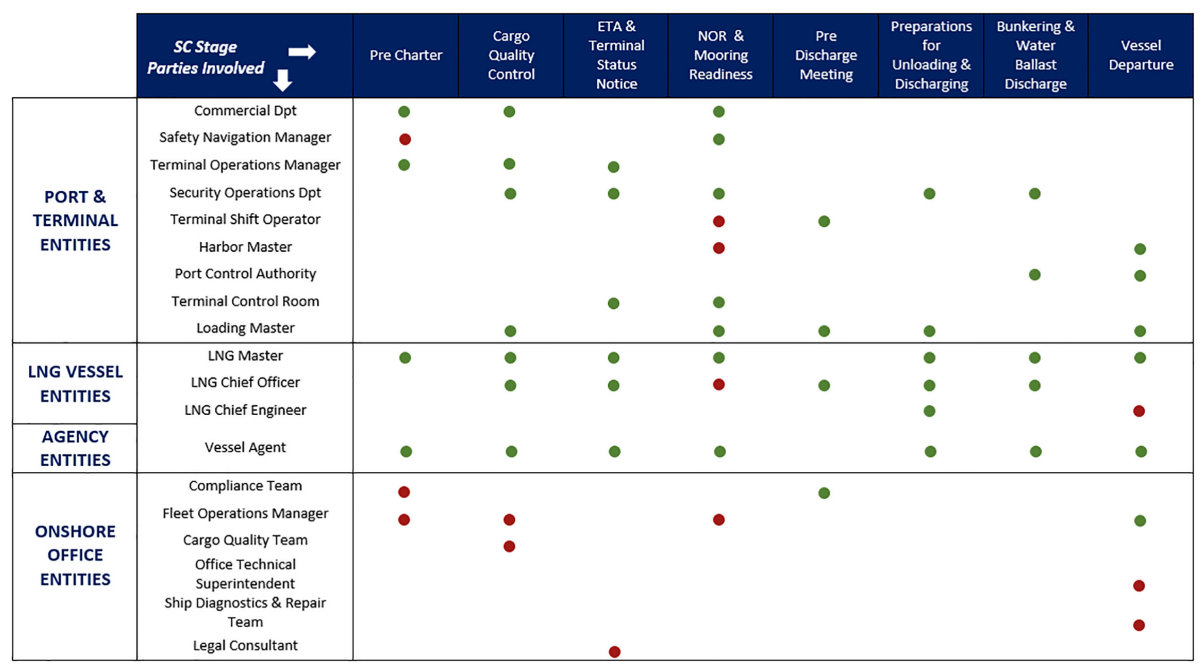

The impact assessment of blockchain

which members, their respective interactions and the data flows that serve as inputs and outputs. Furthermore, it permits process holders and operators to identify errors that trigger lower-level processes to initiate. Consequently, the errors mentioned above in the operations cycle of a single LNG vessel unloading process can be measured. With other required data known and following well-thought, explicit assumptions, a detailed projection can be produced annually for the whole fleet.

The study results can be summarised in Table 1 . The reader can overview the number of the involved members and the processes that need to be initiated manually or in the paper, hence serving as a trigger mechanism for several transactions. It is highlighted how many of these processes are in written communication form or are message-based and may cause time lags and overruns, as mentioned in section 3 of the current paper. The identified processes substantiate the need and possibility to migrate to a permissioned blockchain/smart contracts-based platform for those specific parts of the supply chain. The impact of such a platform differs for each of the examined SC stages without being uniform in terms of extension and practicality. Besides, a set of items, such as the number of configurations, notices, lists and guidelines shared, are listed as inputs/outputs, accessible in the decentralised system according to the permission layer that every participant is entitled to. The information has been thoroughly curated after examining Society of International Gas Tanker and Terminal Operators (SIGGTO) safety handling principles for ships and ports (LGHP on Ships and in Terminals, 2016) and port authorities' handling procedures and guidelines (PIG of Rotterdam, MPM Revithousa), providing the study with a holistic view on the existing practices that may exist on either side of the interface.

Involved parties are highly indicative of the deep integration of the communication flow while making it highly clear for organisations that they need to focus their optimisation techniques and operational streamline on high-frequency participants. By studying Table 1 and Figure 2, the reader can see the cross-sectional modus operandi of this crowded part of the supply chain. In green, standard interactions are indicated as modelled (see Figure 2); in red, additional interactions that refer to involved participants as detected by 4th level modelling, where standard procedures do not run smoothly for many reasons. It is safe to speculate on the complications of such interactions in an end-to-end view of the chain. 
MABR

7,1

56

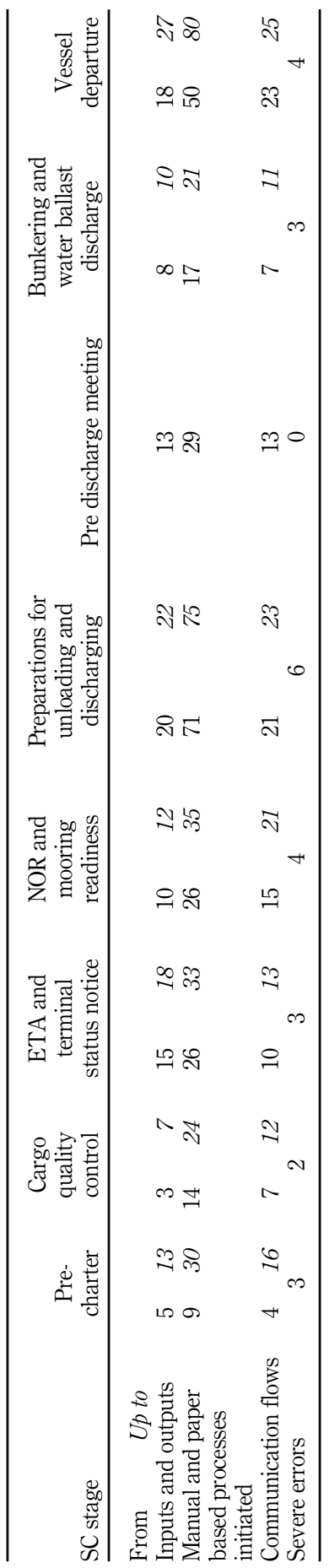

Table 1.

Number of items per stage of one voyage 


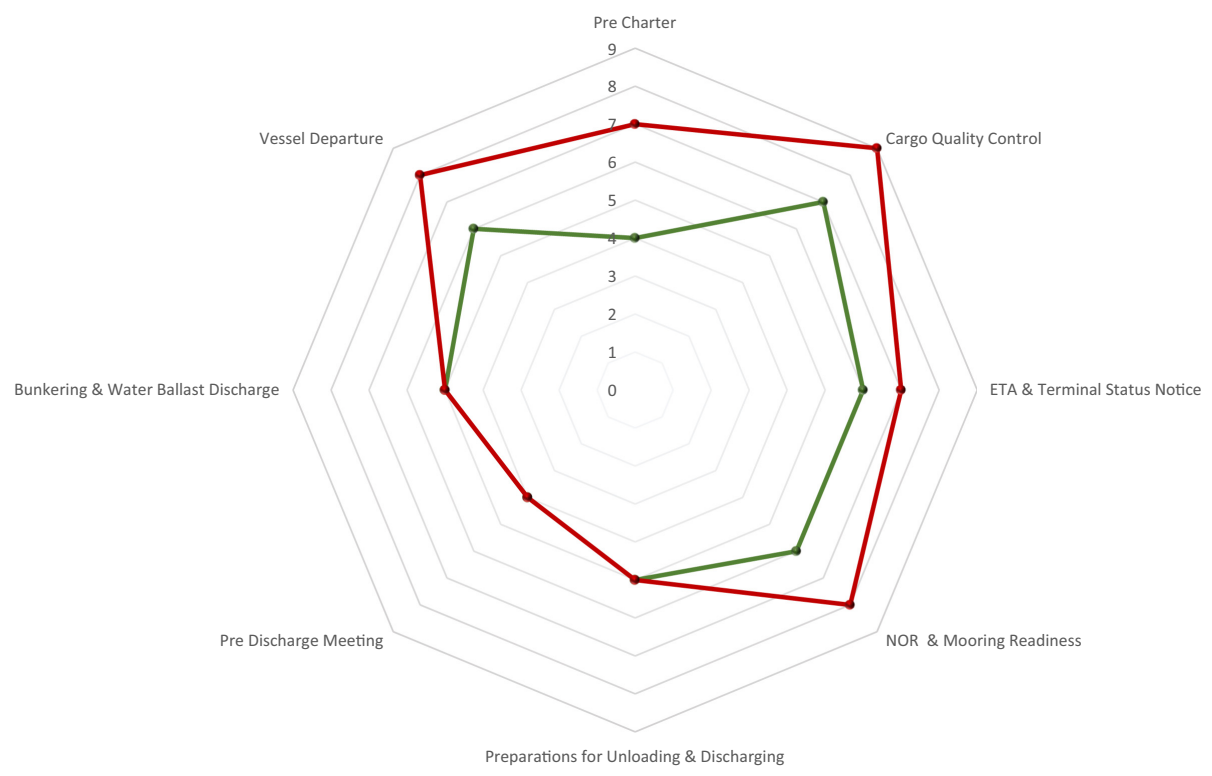

The impact assessment of blockchain

Figure 2.

Entities involved per stage of the supply chain examined

An illustrative version of the abovementioned matrix, in Figure 3, adds to the SC a straightforward view on the most crucial aspects of the examined stages; if one notices the outliers from pre charter to vessel departure. There, a radar chart helps visualise multivariate data, which are used to plot the grouped value of the SC stages over the common variable of the number of the involved embers represented on axes starting from the same point. Cargo quality control, notice of readiness (NOR) and mooring readiness and vessel departure are the most crucial stages of the midstream SC in terms of interaction and time crossovers. The 4 th level process documentation indicates a high number of entities involved during these stages. As such, documentation is facilitated for the maritime company, so selective focus on building an ad-hoc to participant hypeledger fabric can streamline operations.

Following the generic presentation of the midstream LNG supply chain processes, a random shipowner/manager is selected as the data source. The current study opts for a publicly listed entity that provides its investors with data concerning long and mid-term chartered LNG vessels, contract timeframes, fleet allocation and capacity in a detailed manner. The data used in this analysis are drawn from the quarterly report published by the LNG shipping company Gaslog (Gaslog (2020). Of the 33 LNG carriers under Gaslog management, we selected 18 wholly owned, thus excluding 15 under Gaslog's subsidiary, Gaslog Partners LP. Of the 18 selected, 13 LNG vessels (72.2\% of the wholly owned fleet) fulfilling the long-time charter assumption are selected, thus excluding the five deployed in the spot market. Given the yearly financial summary (Gaslog, 2020), it is stated that the spot fleet category contains all vessels that have contracts with an initial duration of less than five years. In contrast, the long-term fleet category contains all vessels with charter party agreements with an initial duration of more than five years, and both categories exclude optional periods (Gaslog, 2020). With the average charter duration based on vessels with charters and excluding spot vessels to account for seven years (Gaslog, 2020), it is safe to proceed on calculations with the fleet of 13 vessels. 


\section{MABR 7,1}

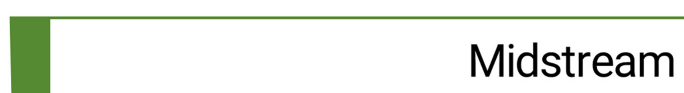

Figure 3.

Number of entities involved per stage of the supply chain examined

The examined fleet's average speed is calculated at 16.5 knots, based both on the design manuals and on current route data (Marine Traffic, 2021). Then the voyage history of each of the vessels is examined so that we can geographically locate areas where the examined fleet operates. However, to overcome the lack of access to the exact voyage history for each of the respective vessels, bolster the confidence level of our sample and ensure that it is representative; we examined the major export terminals and regasification units located in the area of the examined fleet's operation after the data collection (Marine Traffic, 2021). Since the case is about standard round trips from an liquefaction/export terminal to a regasification/import terminal, it is feasible to depict how the fleet spans geographically from export terminals that were detected in the United States of America (USA) (four vessels), Australia (three vessels) and Middle East (six vessels), to the import facilities in Europe, Asia, Eastern Asia and the USA, determining the respective distances among each of the ports, as depicted in Table 2. An analysis of operating days during which the vessels under various charter contracts is presented (Gaslog, 2020). There it is stated that for the year 2020, the company's wholly owned fleet (13 vessels) along with that of its subsidiary, GasLog Partners LP (12 vessels) had a total of 5,924 days. Available days represent total calendar days in the period after deducting off-hire days where vessels are undergoing dry-dockings and unavailable days (i.e. days before and after a dry-docking where the vessel has limited practical ability for chartering opportunities). This number accounts for 237 available days 


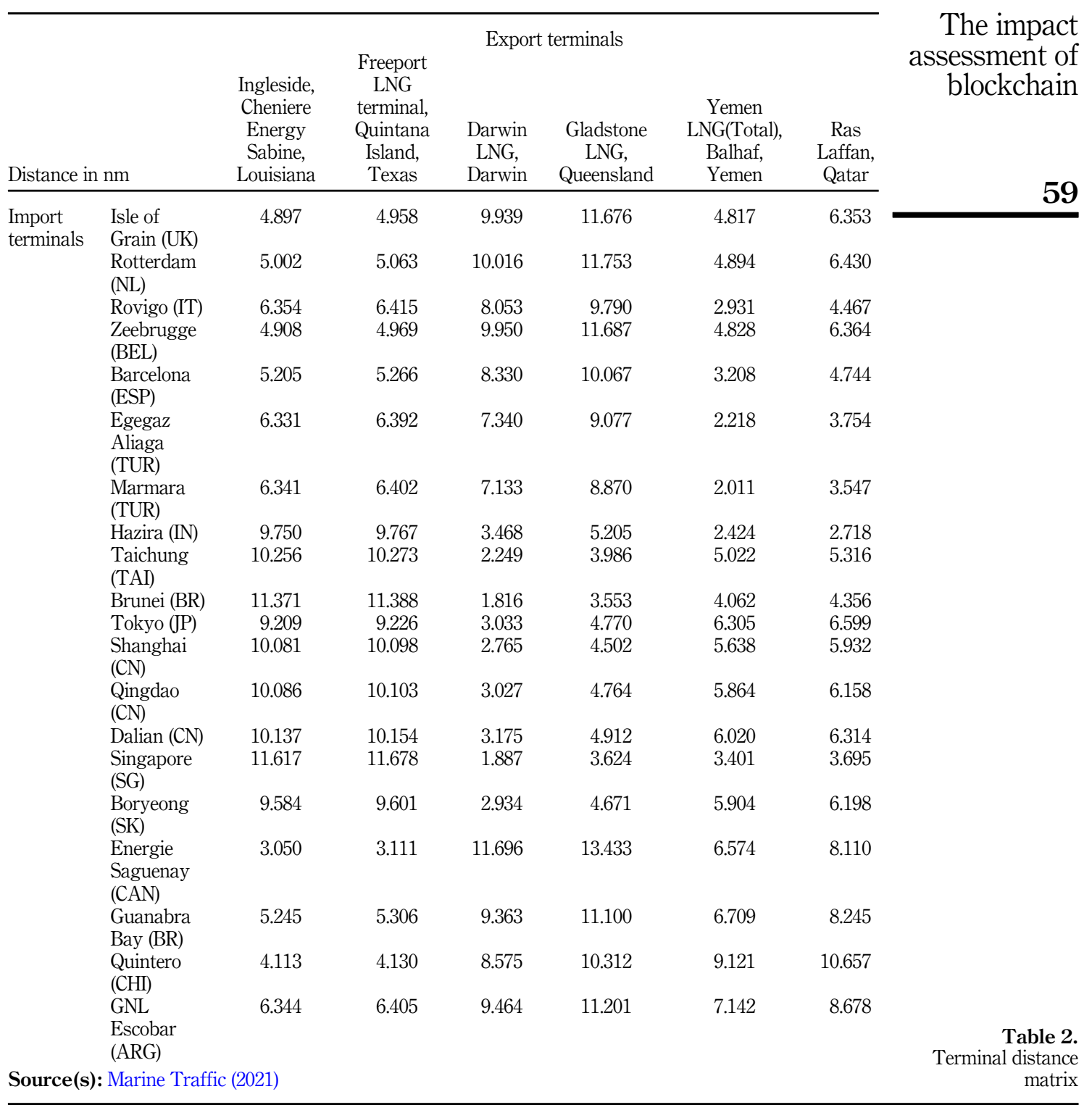

per year, so under the assumption of a $65 \%$ yearly utilisation rate for each vessel, which averages 93,891 miles/year, we can safely figure a yearly round trip number for the fleet in the context of the examined case, which accounts for the proposed allocation displayed in Table 3.

Leveraging the information derived from Table 3 and extrapolating the data from Table 1 and Figure 3, we can collect information for one fiscal year. The comparative data suggest augmented repetition in the examined items on the chartered fleet basis. Hence, we underline the magnitude of the paperwork, cross-sectional information flow genuinely and overrunning 
MABR

7,1

\section{0}

data that urge the need for the implementation of a permissioned blockchain in the type of a hyperledger fabric.

\section{Blockchain evaluation framework for LNG shipping companies}

\subsection{Methodology}

The methodology proposed in the current paper considers previous attempts to explore the implications of blockchain for the supply chain. Di Gregorio and Nustad (2017) addressed the possible introduction of blockchain technology within the shipping industry without distinction between liner and charter markets. Their study opted for semi-structured interviews with representatives from shipping companies, information technology (IT) and public institutions, combined with extensive online research. The qualitative findings conclude that whereas blockchain adoption is still extremely uncertain, it provides businesses with technology adoption scenarios to plan their strategy. However, it fails to examine areas of the supply chain for the implementation of blockchain in a more detailed manner. Mendling et al. (2018) proposed an alternative approach to applying blockchain to existing business processes and explored the impact on existing processes and the creation of new ones through BPM. The rationale was to use blockchain technology to rethink the management of intra-organizational business processes, based on its concept to realise execution without a central party serving as a single point of trust. Not disregarding the impact of this approach, the fact that blockchain is considered a feasible technology to transform business processes can be discussed. However, its feasibility is often a barrier for shipping companies that do not understand blockchain technology and seek quantified benefits to implement it.

The present study adopts a more detailed approach to model the LNG midstream supply chain's business processes. By starting with a higher view of the processes on a more strategic level, the research decomposes them to a more detailed lower level using business process model notation (BPMN) and value-added chain diagram (VACD). After the business processes have been listed and displayed, the organisations/departments involved can be identified, along with specific transactions with their inputs and outputs. In comparison with the previous attempts, the major novelty presented in the current research is the detailed standardised modelling of the midstream LNG supply chain processes using BPM to explore the impact of blockchain implementation.

Underlying the BPM concept, it is the notion that some performed activities lead to a product or service that a company provides to the market. The basis of BPM is the explicit representation of activities and the executional constraints among them in the form of business processes. Perhaps the most identifiable form is a workflow chart or diagram, which maps out the logical flow of processes in a unit or department of the organisation. Some companies prefer the representation to be a map since visualisation and introspection add to

Table 3.

Fleet deployment and yearly trips in the examined case scenario

\begin{tabular}{llccc}
\hline $\begin{array}{l}\text { Loading } \\
\text { region }\end{array}$ & $\begin{array}{l}\text { Export } \\
\text { terminal }\end{array}$ & $\begin{array}{c}\text { Average sailing distance per } \\
\text { year (in nm) }\end{array}$ & $\begin{array}{c}\text { Average round trips } \\
\text { per year }\end{array}$ & $\begin{array}{c}\text { Number of vessels } \\
\text { deployed }\end{array}$ \\
\hline USA & Ingleside & 14.988 & 6 & 6 \\
\multirow{2}{*}{ Australia } & Freeport & 15.071 & 6 & 3 \\
\multirow{2}{*}{ Middle East } & Darwin & 12.421 & 8 & 4 \\
& Gladstone & 15.895 & 6 & \\
& Yemen & 9.909 & 9 & \\
& Ras Laffan & 11.864 & 8 &
\end{tabular}


the model's comprehension. In other cases, the preference is for models, which are highly precise and detailed, and also require much work.

The pliable character of this documentation derives from the BPM lifecycle, which entails process planning and strategy. Qualitative data are used to design and model business processes leading to the documentation and analysis. Obtaining the necessary information in order to measure and evaluate performance comes along monitoring and controlling continually. The last but most crucial step of the examined lifecycle is process refinement or improvement. The overall analysis results are used to 'fine-tune' the processes, and here blockchain implementation is explored for the organisation's benefit.

$\mathrm{BPM}$ is selected as a suitable framework for this purpose as it has been successfully used in multiple industries to model processes related to the supply chain, roles, tasks and working values. It is a useful aid to understand the processes and their interrelationships, organise, analyse and highlight gaps, and enable re-engineering and improvement (Weske et al., 2018). Benedict et al. (2019) described BPM as a set of technologies that can support the management through processes. Rizzi and Di Francescomarino (2020) completed the BPM definition by adding its predictive impact in understanding and improving the existing processes of an enterprise. The use of BPM in the current research follows the rationale of Lyridis et al. (2005), which proposed a framework for BPM implementation in the shipping industry.

Moreover, BPM sustains the proposed methodological framework developed to assess blockchain implementation because it can serve as an edifice for organisation members for future projects or process evaluations. The authors believe that this course of action, reversely to what Mendling et al. (2018) proposed, could establish trust in blockchain technology, trigger pilot applications within the LNG supply chain and LNG shipping companies and be used as a basis to build a testbed and further quantify benefits. The proposed methodological scope addresses even more challenges offering a measurable payback for those who implement it. This payback is measured in percentage reduction in process operating costs, end-to-end process completion time, time to change business requirements and manual operations errors.

\subsection{Modelling the business processes (AS-IS) potential implementation areas for blockchain in the LNG supply chain}

The first step for a successful implementation of BPM is to identify and analyse the situation "AS-IS". This translates to details relevant to the shipping company's operations, workflows, the departments involved and the time and cost of each operation, which will be used as a basis for modelling. In this sub-section, the business operation of a hypothetical LNG shipping group is analysed to extract the business processes. To achieve this, the study adopts a top-down approach towards modelling the midstream LNG supply chain using the AG Software, ARIS Architecture on a computer with an Intel Core i7 8th Gen processor at $1.8 \mathrm{GHz}$ and $8 \mathrm{~GB} \mathrm{RAM}$.

Initially, a comprehensive generic view of the LNG supply chain is presented through a VACD displayed in Figure 4. The VACD demonstrates a higher level of processes and the responsible units for task execution; the IT systems are embedded as data sources for task execution. For the midstream LNG supply chain, the main tasks depicted as processes involve an import terminal, a shipping agency service and an LNG vessel, which is modelled as a single separate entity. The LNG vessel is chartered and transports LNG cargoes to the import terminal, according to a SPA signed between storage capacity holders of the liquefaction plant and buyers in joint venture groups or single gas utilities under state control, to supply the regasified LNG to end-users. Specific units, departments, assembly teams are described. Multiple roles (vessel master, chief officer, chief engineer, etc.) are highlighted because of their authority regarding form evaluation, communication and the gravity of their call against the occurring errors.
The impact assessment of blockchain 
MABR

7,1

62

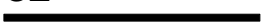

Figure 4.

LNG supply chain value added chain diagram

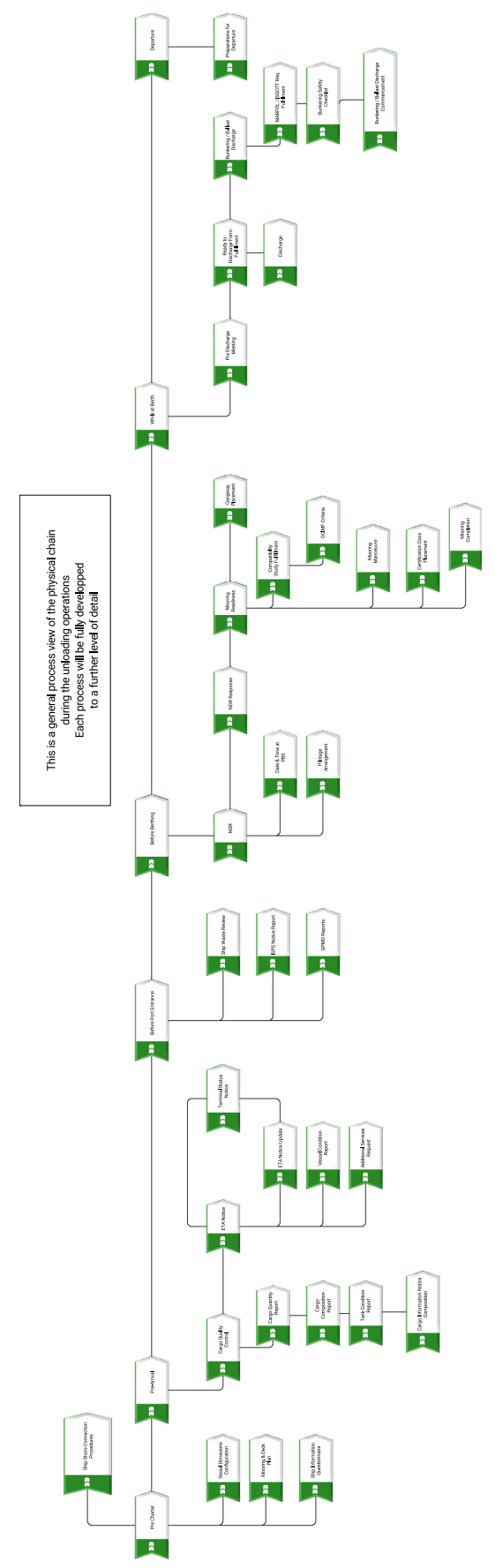


A more detailed view of the midstream LNG supply chain processes is critical for the next steps of designing the future "TO-BE" situation, specifically the re-engineering of processes to include blockchain. Figure 5 focuses on the midstream segment and the ship-shore operations, focussing on the standard actions required by the involved entities. The processes are modelled with reference to the guidelines on ships and terminals published by SIGGTO (Mc Guire and White, 2016).

A more detailed modelling is the focal point of Figures 6 and 7, which depicts the main ship-shore processes via BPMN diagrams. Each business process is related to separate entities (LNG vessel, import terminal and LNGC agent) and their relevant departments and constitute the essence of the analysis; they describe actions, participants and information flows. During pre-chartering activities, standardised information is exchanged between the
The impact assessment of blockchain
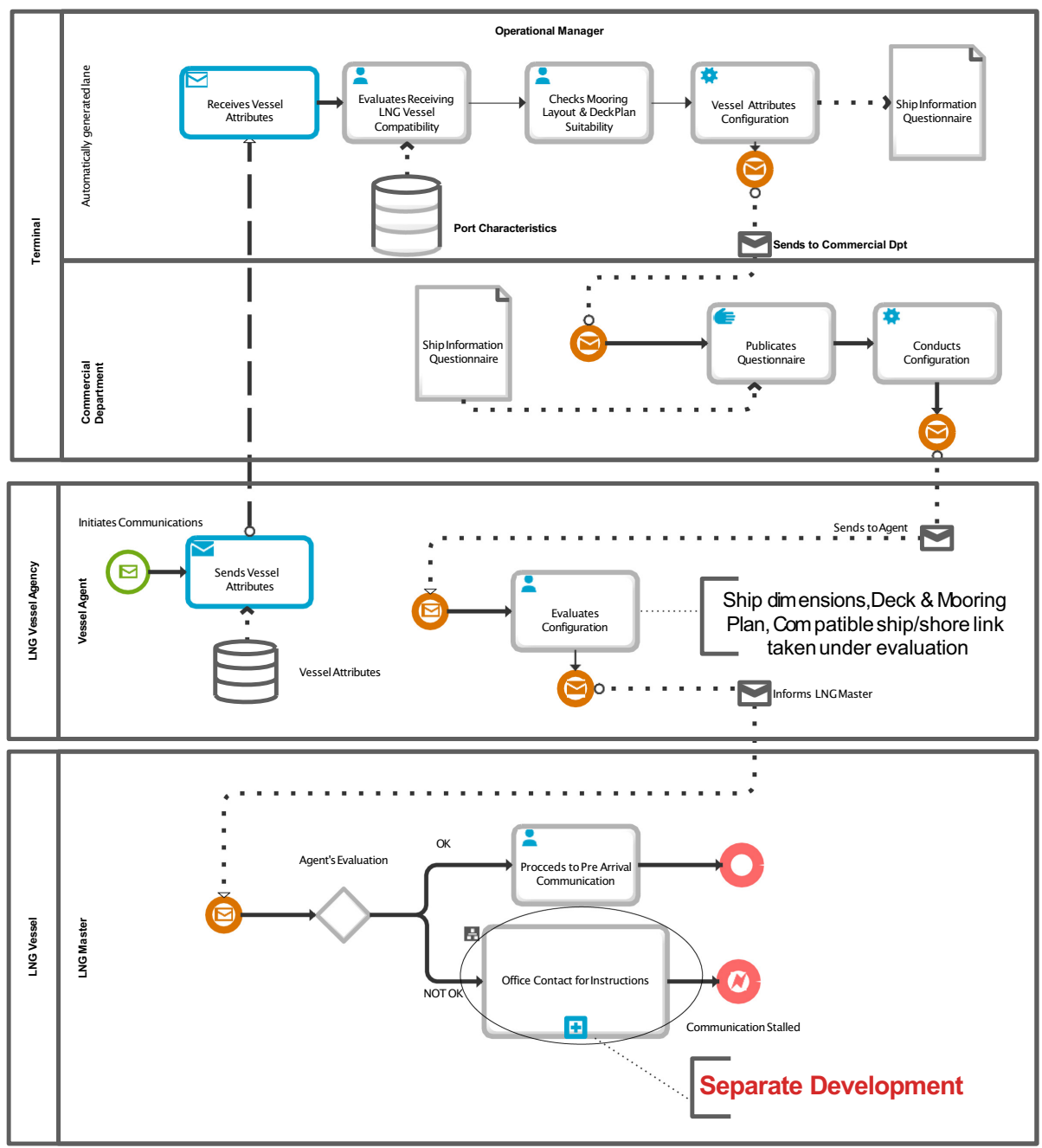

Figure 5.

Ship-shore interface business processes 


\section{MABR \\ 7,1}

64

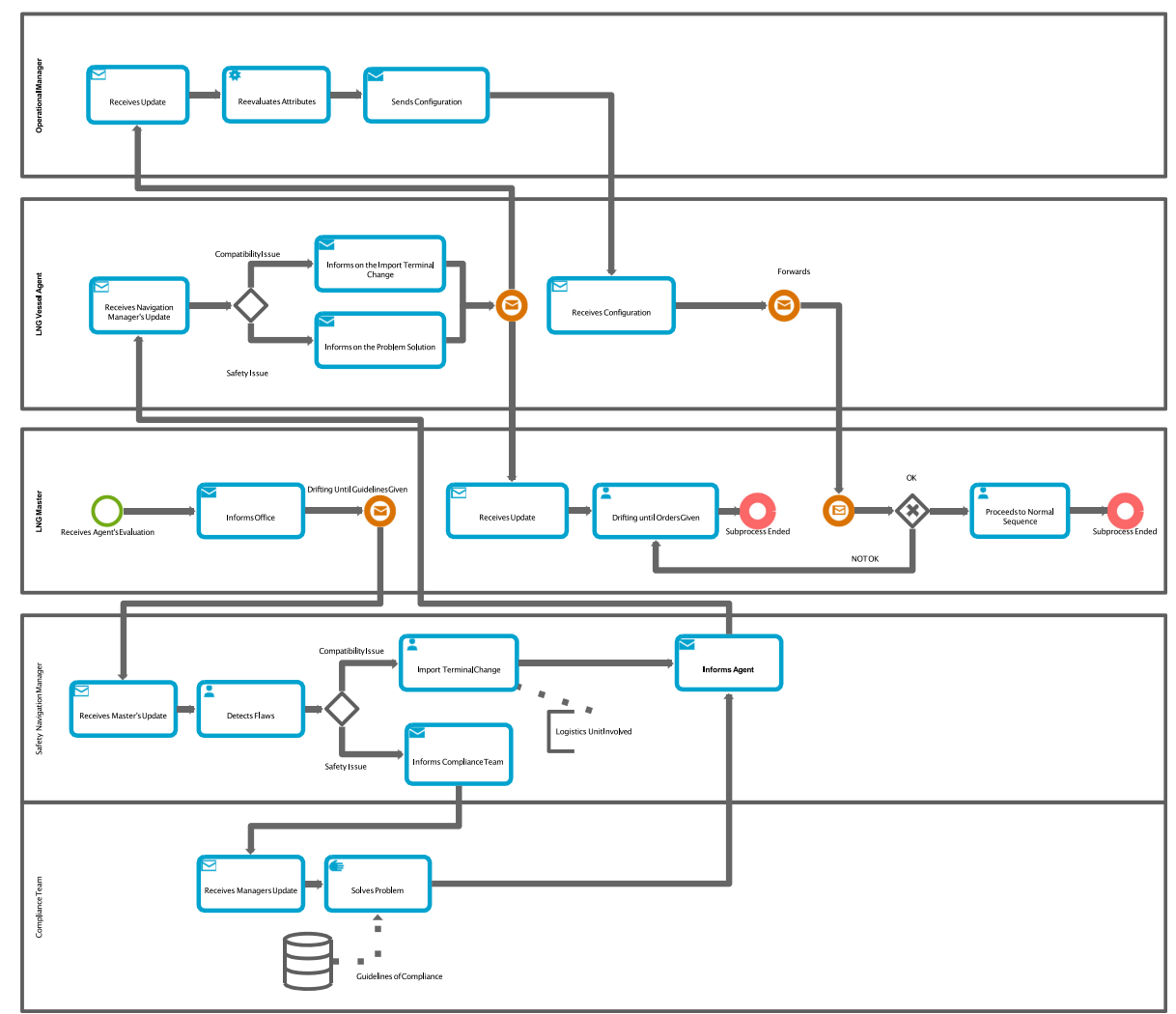

Figure 6.

BPMN diagram for precharter workflow and transactions

terminal operator and the LNG vessel agency, considering vessel attributes and her compatibility with the terminal. The relevant information is gathered by terminal operational manager, checked and configured according to ship's information questionnaire. The results of the configuration mentioned above are to be forwarded to the vessel agency for evaluation and to the LNG master who makes the final call. Task flow, configuration parameters and all of their implicated forms, message flow and the actual decision-makers are distinct in the BPMN diagram of Figure 6. If the LNG master disapproves agency's configuration over the compatibility criteria as Figure 5 indicates, the import terminal safety navigation manager's communication with the agent is enabled under operations department oversight while the vessel is drifting. During this, the most common scenario is communication with the office, which corresponds to the entity of the LNG company that operates the vessel, as depicted in Figure 7.

\subsection{Potential implementation areas for blockchain in the LNG supply chain}

Regarding transactions, a blockchain smart contract can be signed between two trading parties, complementary to a traditional SPA. For the midstream LNG supply chain, it can be applied as highlighted in Figures 6 and 7. A smart LNG contract may impose access restrictions so that only a selected party can alter the number abates fraud attempts. For instance, the buyer of an LNG cargo of specific volume and quality from the seller will sign the 

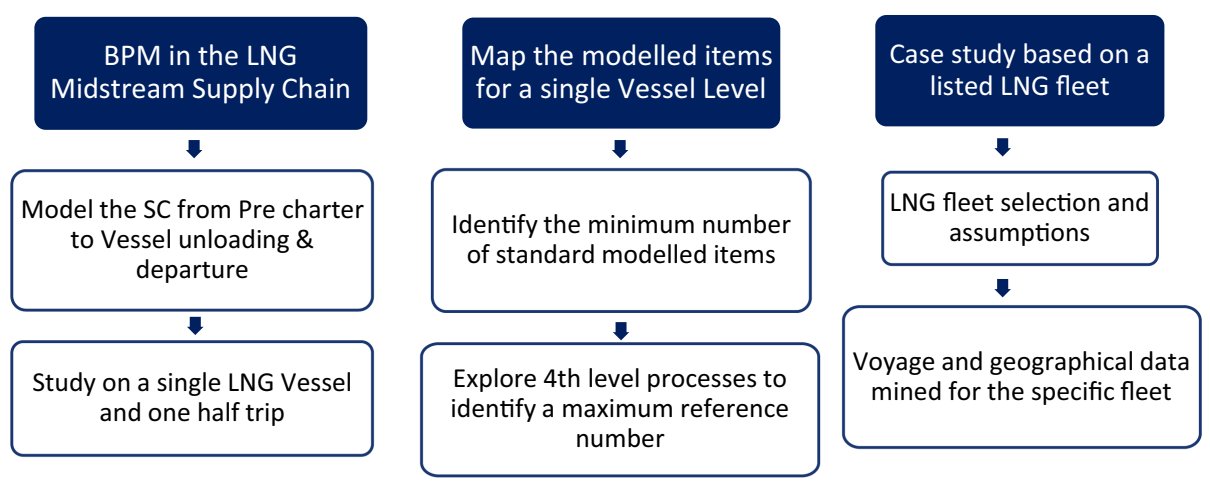

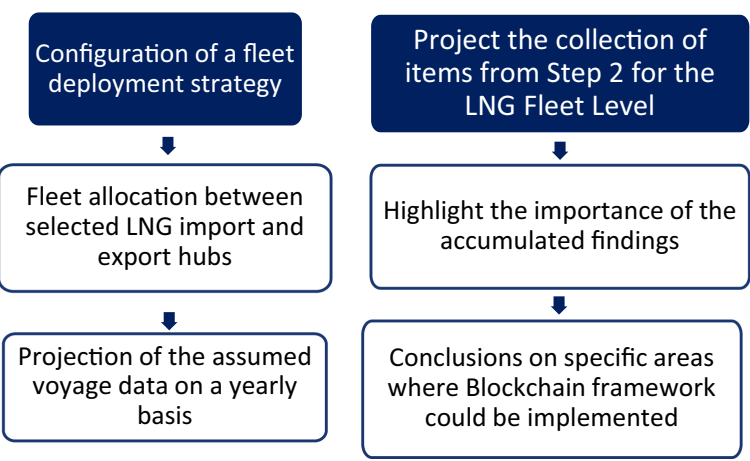

Figure 7.

BPMN diagram for office communications regarding pre-charter workflow and transactions

cargo documents using cryptographic methods, like a digital fingerprint, with trustworthy information about the LNG quality set in the SPA and charter party documents. In this way, it can be checked if the LNG volume and quality match its signature.

Concerning the pre-charter processes Figures 6 and 7 indicate that information exchanged via documentation (port restrictions and jetty receiving capabilities) can be digitised in a blockchain. Furthermore, the formal receipt of the ship's mooring plan and equipment, deck layout, gas handling systems and the ship information questionnaire can also be digitised with access shared between the LNG shipping company, the terminal operator and the charterer of the vessel. The inherent characteristic of a blockchain-based application, which enables automated, yet permissioned sharing of data can counter issues such as flawed or not verified data and questionnaire deficiencies. Time savings associated with automated exchange of documents via blockchain may lead to reduction of laytime at anchorage and consequently to cost overruns. Another indirect positive impact of blockchain may lead to critical time windows during the operation of a vessel, which can be exploited by the shipowner to service opportunistic spot cargoes.

The business processes are subject to rules on how to respond to specific conditions. If, for instance, the seller does not deliver the LNG cargo within the time windows defined in the relevant clauses of the SPA, the buyer might be entitled to receive a penalty payment. Blockchain smart contracts can be executed to monitor the contract's execution from each party's perspective, and encryption can ensure that the data is readable only for the parties involved in the LNG trade. 
MABR

7,1

\section{6}

\section{Conclusions}

The proposed conceptual methodology can be used to assess the implementation of blockchain application in the midstream LNG supply chain. By implementing the methodology, stakeholders can quantify the possible impact of blockchain on the operational performance of each stakeholder's operations separately and the supply chain as a whole. Impacts may include less total time for operations and processing documents, transparency between stakeholders and better assets' utilisation due to sharing resources of possible collaborations among entities of maritime logistics of LNG.

Although the blockchain adoption rate does not correspond with its qualities, potential benefits and showstoppers must be identified to enable decision-makers to make informed decisions. The present study's motivation and ambition were to contribute to the cause mentioned above by thoroughly examining the LNG supply chain areas. BPM was utilised to model the supply chain processes and implemented with the ARIS Architecture software to achieve this.

The VACD and BPMN diagram demonstrate the LNG supply chain's stakeholders and departments, focussing on pre-charter processes. The relationship between the physical supply chain's major components is illustrated as a standardised process for optimal efficiency and repeatability. Furthermore, modelling the ship-shore interface tracks all transactions between the LNGC, LNG vessel agent and port-terminal operator, revealing the issue of abundant documentation forms, excessive paperwork and communication imbroglios. The introduction of blockchain can reduce bureaucracy and paperwork.

Except for time savings, high transaction volumes may decrease transparency as most of these documents fail to provide real-time visibility and data quality, causing setbacks in financial settlements. The nature of permissioned sharing information between blockchain participants can reduce data entry errors and improve fraud detection, thanks to the real-time tracking and monitoring of the LNG cargo documents. The information stored in the blockchain is impossible to delete or edit without leaving traces, so record transparency and transaction clarity is ensured.

In light of the wider adoption of blockchain from the LNG industry, BPM can provide organisations with a valuable framework to evaluate how blockchain could disrupt their operations. Thus, the blockchain implementation's improvements or weaknesses can be pinpointed and provide the interested stakeholder of the LNG supply chain with specific feedback.

The research has certain limitations deriving from its conceptual nature. Despite the attempt for quantification of transactions that has been conducted for the supply chain segment under study, the business processes' modelling is based on standard procedures described in the guidelines by SIGGTO and may need further adjustment for specific applied cases. Albeit the limitations, there is a clear indication of the process holders that influence process execution on high frequency and could be used as nodes in the blockchain system. Furthermore, the standardised volume of paperwork, including SPAs, forms, protocols, etc., underlines smart contracts' potential. Although most of it is required for safety, quality, and other reasons, the manner in which they are significantly processed impedes organisational efficiency in operations while causing severe time lags and cost overruns. Quantitative results, including related time and cost savings, could be acquired by shipping companies through interviews, questionnaires and real-time data access, thus advancing the research. Finally, the identified errors map the areas of improvement where the extra focus should be put to streamline SC operations. They also highlight the excessive need for process reengineering by implementing emerging technologies like blockchain to reduce unnecessary losses in specific parts of the supply chain while staying relevant to the ever-evolving business dynamics. 
Notwithstanding its limitations, it is to the authors' belief that the paper not only meets its objectives but will trigger further research to apply the proposed methodology and quantify the benefits from its application.
The impact assessment of blockchain

\section{References}

Andreadis, G.O., Papaleonidas, C. and Dimitrios, V.L. (2020), "Evaluating the operations of an LNG shipping company with business process modelling", Paper Presented at the SNAME 7th International Symposium on Ship Operations, Management and Economics, Virtual, April 2021, doi: 10.5957/SOME-2021-018.

Bajpai, P. (2017), "How IBM and Maersk will use the blockchain to change the shipping industry", Nasdaq, available at: https:/www.nasdaq.com/articles/how-ibm-and-maersk-will-useblockchain-change-shipping-industry-2017-03-06 (accessed 6 November 2020).

Benedict, T., Kirchmer, M., Scarsig, M., Frantz, P., Saxena, R., Morris, D. and Hilty, J. (2019), BPM CBOK Version 4. 0: Guide to the Business Process Management Common Body of Knowledge, ABPMP, Vol. 2019.

Chambers, S. (2018), "HSBC, ING and Cargill in landmark blockchain soya shipment - Splash 247", available at: https://splash247.com/hsbc-ing-cargill-landmark-blockchain-soya-shipment/ (accessed 6 November 2020).

Clarksons Shipping Intelligence (2021), available at: https://sin.clarksons.net/ (accessed 17 February 2021).

Crosby, M., Nachiappan, Pattanayak, P., Verma, S. and Kalyanaraman, V. (2016), "Blockchain technology: beyond bitcoin”, Applied Innovation Review, No. 2, pp. 6-19.

Di Gregorio, R. and Nustad, S.S. (2017), "Blockchain adoption in the shipping industry", Unpublished MSc Thesis, Copenhagen Business School, Copenhagen.

Furness-Smith, G. (2017), "MOL, NYK and K Line to develop trade data sharing platform using blockchain", available at: https://loydslist.maritimeintelligence.informa.com/LL111092/MOLNYK-and-K-Line-to-develop-trade-data-sharing-platform-using-blockchain (accessed 6 November 2020).

Gas Log Ltd (2020), "Annual and quarterly reports", available at: https://www.gaslogltd.com/ investors/annual-quarterly-reports/ (accessed 2 March 2021).

GIIGNL (2020), The LNG Industry GIIGNL Annual Report.

Han, C. and Lim, Y. (2012), LNG Processing. From Liquefaction to Storage. Computer Aided Chemical Engineering, Vol. 31, Elsevier B.V, Singapore, doi: 10.1016/B978-0-444-59507-2.50013-5.

Iansiti, M. and Lakhani, K.R. (2017), "The truth about blockchain”, Harvard Business Review, Vol. 95 No 1, pp. 118-127.

Jensen, T., Hedman, J. and Henningsson, S. (2019), "How TradeLens delivers business value with blockchain technology”, MIS Quarterly Executive, Vol. 18 No. 4, pp. 221-243, doi: 10.17705/ 2msqe.00018.

Jeston, J. (2018), Business Process Management Practical Guidelines to Successful Implementations, 4th ed., Routledge.

Kang, T.-J. (2017), "HMM completes pilot blockchain voyage with reefer-laden box ship", available at: https://lloydslist.maritimeintelligence.informa.com/LL111275/HMM-completes-pilot-blockchainvoyage-with-reeferladen-boxship (accessed 6 November 2020).

Ledesma, D. and Fulwood, M. (2019), "New players, new models", available at: https://www. oxfordenergy.org/wpcms/wp-content/uploads/2019/04/New-Players-New-Models.pdf.

Lin, I.-C. and Liao, T.-C. (2017), "A survey of blockchain security issues and challenges”, International Journal of Network Security, Vol. 19, pp. 653-659, doi: 10.6633/IJNS.201709.19(5).01.

Lyridis, D.V. and Papaleonidas, C. (2019), "Organization and management of tanker shipping companies", in Panayides, P.M. (Ed.), The Routledge Handbook of Maritime Management, Routledge, pp. 58-79. 
MABR

7,1

68

Lyridis, D.V., Fyrvik, T., Kapetanis, G.N., Ventikos, N., Anaxagorou, P., Uthaug, E. and Psaraftis, H.N. (2005), "Optimising shipping company operations using business process modelling”, Maritime Policy and Management, Vol. 32 No. 4, pp. 403-420, doi: 10.1080/03088830500300636.

Marine Traffic (2021), available at: https://www.marinetraffic.com/ (accessed 17 February 2021).

Mc Guire, W. (2016), Liquefied Gas Handling Principles on Ships and in Terminals, (LGHP4), 4th Edition \& Co, London, pp. 9-12.

McCaw, M. (2018), "Energy looks to blockchain for efficiency gains", Petroleum Economist, available at: https://www.petroleumeconomist.com/articles/upstream/technology/2018/energy-looks-toblockchain-for-efficiency-gains (accessed 6 November 2020).

Mendling, J., Weber, I., Van Der Aalst, W., Brocke, J.V., Cabanillas, C., Daniel, F., Debois, S., Di Ciccio, C., Dumas, M., Dustdar, S., Gal, A., García-Bañuelos, L., Governatori, G., Hull, R., La Rosa, M., Leopold, H., Leymann, F., Recker, J., Reichert, M., Reijers, H.A., Rinderlema, S., Solti, A., Rosemann, M., Schulte, S., Singh, M.P., Slaats, T., Staples, M., Weber, B., Weidlich, M., Weske, M., $\mathrm{Xu}, \mathrm{X}$. and $\mathrm{Zhu}$, L. (2018), "Blockchains for business process management - challenges and opportunities", ACM Transactions on Management Information Systems, Vol. 9, doi: 10.1145/3183367.

Papaleonidas, C., Androulakis, E. and Lyridis, D.V. (2020), "A Simulation-based planning tool for floating storage and regasification units”, Logistics, Vol. 20204 No. 4, p. 31, doi: 10.3390/LOGISTICS4040031.

$\mathrm{Pu}$, S. and Lam, J.S.L. (2020), "Blockchain adoptions in the maritime industry: a conceptual framework", Maritime Policy and Management, pp. 1-18, doi: 10.1080/03088839.2020.1825855.

Reuters (2018), "US Soy Cargo to China traded using blockchain", Reuters, available at: https://www. reuters.com/article/grains-blockchain/u-s-soy-cargo-to-china-traded-using-blockchainidUSL8N1PG0VJ (accessed 6 November 2020).

Rizzi, W., Di Francescomarino, C. and Maggi, F.M. (2020), "Explainability in predictive process monitoring: when understanding helps improving", in Fahland, D., Ghidini, C., Becker, J. and Dumas, M. (Eds), Business Process Management Forum. BPM 2020. Lecture Notes in Business Information Processing, Springer, Cham, Vol. 392, doi: 10.1007/978-3-030-58638-6_9.

Shen, M., Zhu, L. and Xu, K. (2020), Blockchain and Data Sharing, doi: 10.1007/978-981-15-5939-6_2.

Trimble, N. (2018), "Changing LNG markets and contracts", Journal of World Energy Law and Business, Vol. 11 No. 5, pp. 427-439, doi: 10.1093/jwelb/jwy024.

Tusiani, M.D. and Shearer, G. (2016), LNG: A Nontechnical Guide, PennWell.

Wei (2017), "PIL and PSA jump on the blockchain bandwagon with IBM", Lloyd's List, available at: https://loydslist.maritimeintelligence.informa.com/LL110930/PIL-and-PSA-jump-on-theblockchain-bandwagon-with-IBM (accessed 6 November 2020).

Weske, M., Montali, M., Weber, I. and vom Brocke, J. (2018), "BPM: foundations, engineering, management”, Lecture Notes in Computer Science, Vol. 2018, Springer-Verlag, Sydney, pp. 3-11.

Xu, L., Chen, L., Gao, Z., Chang, Y., Iakovou, E. and Shi, W. (2018), "Binding the physical and cyber worlds: a blockchain approach for cargo supply chain security enhancement", 2018 IEEE International Symposium on Technologies for Homeland Security, HST 2018 1-5, doi: 10.1109/ THS.2018.8574184.

Zeng, X. (2017), "HMM completes first blockchain Pilot Voyage”, available at: https://fairplay.ihs.com/ container/article/4291331/hmm-completes-first-blockchain-pilot-voyage (accessed 6 November 2020).

Zoolfakar, M.R., Norman, R., Mesbahi, E., Dahalan, W.M. and Puteri Zarina, M.K. (2014), "Holistic study of liquefied natural gas carrier systems", Procedia Computer Science, Vol. 36 No. C, pp. 440-445, doi: 10.1016/j.procs.2014.09.018.

\section{Further reading}

Energy Web (2020), “Annual report”, available at: https://www.energyweb.org/insights/annualreports/2020-power-forward/ (accessed 2 March 2021). 
IGU (2020), 2020 World LNG Report.

Mokhatab, S., Mak, J.Y., Valappil, J.V. and Wood, D.A. (2013), Handbook of Liquefied Natural Gas. Handbook of Liquefied Natural Gas, Elsevier, doi: 10.1016/C2011-0-07476-8.

Shrivas, M.K. and Yeboah, T. (2019), "The disruptive blockchain: types, platforms and applications", Texila International Journal of Academic Research, Special Edition, pp. 17-39, doi: 10.21522/ TIJAR.2014.SE.19.01.Art003.

\section{About the authors}

Dimitrios V. Lyridis is an Associate Professor in the area of Maritime Transport in the School of Naval Architecture and Marine Engineering (NA\&ME) at the National Technical University of Athens (NTUA). He is currently Head of the Laboratory for Maritime Transport (LMT) of NTUA. He has a Diploma (1987) in NA\&ME from NTUA (1987), an MS (1990) in NA\&ME (Marine Systems Management) from the University of Michigan (UM), an MSE (1990) in Industrial and Operations Engineering (IOE) from UM, and a Ph.D. (1990) in NA\&ME from UM as well. His main scientific areas of interest are maritime economics and logistics, shipping finance, maritime transportation and energy. He has undertaken a large number of research projects in maritime transport, shipping finance, and energy (including cost benefit analyses for investment projects) and he has been involved in applied commercial projects in the areas of ship investment, restructuring, marketing, business and operational planning (including feasibility studies and business plans) for Small and Medium Enterprises (SME's) in the EU and in developing countries.

Georgios O. Andreadis holds a diploma of Naval Architecture and Marine Engineering from the National Technical University of Athens (NTUA), Greece, currently serving in the Hellenic Navy. While at university, he savoured the operational structure of several Chinese shipyards and the seaman's life through a two-month embarkation. Completing his studies in the projected time enabled him to participate as a research associate of the Laboratory of Maritime Transport (NTUA), focussing on the maritime Supply Chain Operations and their optimisation. With his main research interests to be related to economic and managerial issues of maritime nature, supply chain management; focussing on the LNG value chain and its operations digitalisation, he perceived the emergence of the digital shift though businesses and organisations more as a necessity rather than a trend; a fact he is trying to highlight with his affiliation to academic publications and his international maritime conferences presence.

Christos Papaleonidas holds a diploma of Mechanical Engineering and a MSc of Naval and Marine Technology and Science both from the National Technical University of Athens (NTUA), Greece. He is a researcher and $\mathrm{PhD}$ Candidate at the School of Naval Architecture and Marine Engineering, NTUA conducting research on LNG Supply Chain Modelling and Optimisation. He has been participating as a research engineer of the Laboratory Maritime Transport, in multiple European-Funded Projects focussing on Shipping and Energy. His main research interests are related to economic and managerial issues of maritime operations, maritime supply chain management focussing on the LNG value chain. Christos Papaleonidas is the corresponding author and can be contacted at: cpapaleonidas@naval.ntua.gr

Violetta Tsiampa is a Supply Chain Analyst with more than one year of experience working in a globally leading company in medical technology field. Violetta graduated from the National Technical University of Athens in 2017 with a Bachelor's and Master's Degree in Mechanical Engineering. While in school, she wrote her thesis, studying the various business processes and operations of a Container Terminal in the largest Port of Greece. After graduation, she worked as a Research Assistant in the Laboratory for Maritime Transport at School of Naval Architecture and Marine Engineering. In 2019, she obtained her second Master's Degree in International Business with specialisation in Supply Chain Management, at Maastricht University. She wrote her academic thesis combined with an internship, dealing with the Resource Allocation optimisation in an R\&D environment within a Project Management perspective. Violetta is interested in topics related with supply chain and operations management, maritime and port logistics, and new technologies.

For instructions on how to order reprints of this article, please visit our website:

www.emeraldgrouppublishing.com/licensing/reprints.htm

Or contact us for further details: permissions@emeraldinsight.com

The impact assessment of blockchain 